\title{
Learning Authentic Leadership In New Zealand: A Learner-Centred Methodology And Evaluation
}

\author{
Maree Roche, Waikato Institute of Technology (WINTEC), New Zealand
}

\begin{abstract}
This study provides preliminary examination of the efficacy of the "Best Authentic Leadership Self" exercise. A field quasi-experimental design was conducted with a dual purpose: 1) to ascertain the value of interventions aimed at triggering events to enhance the learning (c.f. teaching) of 'authentic leadership' and how this aided, or otherwise, students writing of a "Best Authentic Self" narrative (and subsequent leader development plan) and 2) a content analysis of students' "Best Authentic Self" narratives was undertaken to ascertain commonalities, if any, in authentic leadership learning. The findings support a learning orientation to authentic leadership, with relationships featuring as key to students' authentic leadership development. Finally, limitations in terms of replication are discussed with recommended measures to be adopted. Implications for practice and future direction are discussed.
\end{abstract}

Keywords: Authentic leadership, Learning, Best Self Exercise, Self-Development

\section{INTRODUCTION AND BACKGROUND}

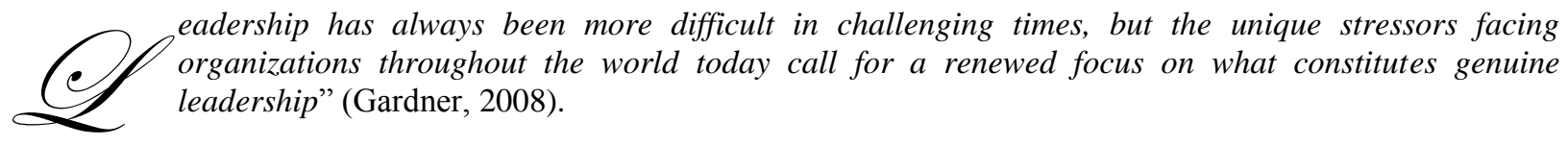

"Business schools assume simple formulas to complex issues are what leaders of today need....but just look where this approach has gotten us - ethical meltdowns, corruption and lacking real world wisdom - we have a leadership crisis that business schools have added to...." (Holland, 2009).

Public, private, and even volunteer organizations, are addressing challenges that run from ethical meltdowns, to terrorism, to financial crisis, to global recessions. Further, what constitutes the normal range of functioning in these conditions is constantly shifting upwards as new challenges, technologies, market demands, generational differences in workers, skill shortages and competition emerge (Erickson, 2009; Dychtwald, Erickson, Morrison \& 2006; Avolio \& Gardner, 2005). The complexity of issues facing leaders today has been described by McKenna, Rooney \& Boal, (2009) as unprecedented and challenging in that 'constant change, information overload, competing and contradictory explanations of problems, seeming incommensurable commercial and ethical demands, create an environment of leader ambiguity and complexity requiring increased demand on leaders to act and rely on their own knowledge, self knowledge (pg 181). Erickson (2009) states that, "Future leaders in all spheres will have to contend with a world with infinite limits, no easy answers, and the sobering realization that we are facing significant, seemingly intractable problems on multiple fronts". Further, the current recession, continuing falling share and stock prices, the late call for greater control and regulation in the US, and the loss of superannuation savings for many, has created a further backlash against what some have argued, is the direct result of corporate greed and leadership that lacks integrity (Time, 2008). Vella-Brodrick \& Page (2009) draw focus to the importance of meaning, authenticity and being 'real' in leadership, as particularly important in the ambiguous and changing times, such as those we are presently experiencing; that is, all these authors suggest that it is the leaders within these organisations that provide for consistency in complex, challenging and changing times. 
However, Holland (2009) suggests that business schools have simplified the complexity of issues emerging leaders will face, that business schools are too detached from real world issues and believe scientific formulas create answers, when in reality, the solutions are complex. She suggests that leadership students, once they graduate, will face ever increasing complexity of issues, defunct of simple answers and formulas and when combined with their lack of self awareness, will raise concern about the next generation of leaders.

\section{AUTHENTIC LEADERS AND LEADERSHIP}

Authenticity, at its core, is about consistency and a commitment to winning oneself by knowing oneself. An authentic leader's ongoing commitment to understanding the drivers to self, such as purpose, values, relationships and integrity, are important in understanding this consistency. The underlying rational is that an 'authentic' and 'real' leader becomes the stable force in a constantly changing world. Moreover, authentic leadership focuses on the substance of positive leadership actions. The positive consequences for organisations of 'authentic leadership' have been highlighted through increased engagement, increased trust, reduced turnover, increased culture and team abilities, and decreased bullying and victimisation (George 2003: 2007; Endrissat, Muller \& Kaudela-Baum, 2007; Grover \& Moorman 2007; Harvey, Martinko, Gardner 2006; Shirley 2006: 2009; Avolio \& Gardner 2005; Avolio, Gardner, Walumbwa, Luthans \& May 2004; Gardner, Avolio, Luthans, May \& Walumbwa 2005; Goffee \& Jones 2005; Ilies, Morgeson \& Nahrang 2005; Michie \& Gooty 2005; Luthans 2006; Macick-Frey, Quick \& Cooper, 2009; Sosik, Jung \& Dinger, 2009 ; Mazutis et al., 2006; Walumbwa, Avolio, Gardner, 2008; Wernsing and Peterson 2008; For a review of authentic leadership, see Special Issue, Leadership Quarterly, 2005).

In developing the theory of authentic leadership, scholars relied heavily on the work of Kernis. Kernis (2003) operationalized the concept of psychological authenticity in terms of three aspects: cognitive (self awareness and unbiased processing), behavioural (behaving congruently with self awareness) and social (enhanced relationship as a result of the above). A key implication for Kernis is that authenticity matters, not only in cognitive and behavioural manifestations, but in relational aspects. Authentic individuals will likely possess the capacity to develop more valuable and meaningful exchanges with peers and followers (Kernis 2003), explaining why the "authentic" person (their cognitive and behavioural implications) is a core in leadership stability (relational aspects of authenticity) (Novicevic et al 2006).

\section{PERSON CENTRED AUTHENTICITY}

The term authenticity is however intrapersonal in focus, is highly individualised, and by knowing how one's personal experiences, be they thoughts, needs, motivations, beliefs and preferences, are captured, is to 'know oneself". It is only when a person "knows oneself", they can display oneself, via the behavioural component of authenticity i.e. when one "acts in accord with the true self. The authentic person is then expressing oneself in ways that are consistent with their own inner thoughts and feelings" (Harter, 2002 p. 382).

Recognition of the self-referential nature of authenticity is critical to understanding authentic leadership. It starts first with understanding the 'authentic self' via self awareness. Erickson (1995), further qualifies the references to authenticity and inauthenticity with the term "relative". Erickson (1995) \& Heidegger (1962) describe authenticity not as an either/or condition, i.e., people are never entirely authentic or inauthentic, instead they can more accurately be described as achieving levels of authenticity. Therefore, psychologists recognize that development of authenticity is non-dualistic (for example one cannot separate good and bad), non linear and dialectic (contradictory and opposing forms operate on the person). Authenticity thus can be recognized in moments or experiences of authentic, or in authentic experience, for example.

In terms of the developmental aspect of 'winning oneself' the central focus is on leadership development and forms a central part of leadership learning in academic and practitioner based programmes. Leadership development has become one of the fastest growing areas in leadership more generally and has experience phenomenal growth in recent times (Ardichvili \& Manderschid, 2008). However, it has been argued that development of a leader/person is not an aspect of leadership that can be 'taught', particularly in terms of issues such as integrity, wisdom and authenticity (Grint 2007), that the above researchers suggest is necessary for leaders today. 
Grint (2007) suggests that leadership development within these highly personal areas can only have learning, and not teaching, focus to it and that leadership is about gaining wisdom, not knowledge. Based on Aristotelian framework aimed at enhancing this, Grint proposed three areas of a leadership development framework each offering separate outcomes: techne, episteme and phronesis. He (and colleagues) suggests that most leadership and leadership development courses have only two of the three requisites. Institutions can teach the techne, the skills of leadership such as emotional intelligence and vision etc., the episteme i.e. the theory of research and body of knowledge (such as theories of situational leadership, authentic leadership etc) but the actual phronesis, that is experience and wisdom to read and understand situations and self reactions, can only be learned by experience and cannot therefore be a classroom or instructor based exercise. Thus "leadership development can only be learned though one's own life experiences" (Grint 2007 p 272).

Authentic leadership scholars tend to agree. For example, Luthans, Youssef and Avoilo (2006) stated "authenticity development is a personal and dynamic process" (pg 51). Further they suggest authentic leadership development may involve "multiple selves that are discovered, explored and tested within multiple social contexts and diversified interpersonal relations". They also explain a pitfall of authenticity would be to assume that there is a non-changing and singular self. In terms of developing authenticity, Luthans et al. (2006), contend that people possess multiple selves, some actual and some possible. In order to enhance their authenticity, people do not just need to discover a true, actual self that is hidden somewhere, but they need to employ their self-awareness and self development strategies to realistically understand the strengths and limitations of their actual and potential selves. As they gradually strive towards a desirable, challenging, but obtainable self (or possible set of selves) the actual self tends to adapt, grow and develop. Hence, over time, the possible self becomes actualized into the true self. In that sense authenticity has been developed. This process of self awareness, possible and actual self, was used by Harter (2002) in counseling adolescents with promising results. However, it has not been used and assessed in authentic leadership development within a traditional learning /teaching environment.

Finally, although the self awareness surrounding one's authenticity is intrapersonal in nature, scholars have suggested that it is important for developing leaders to recognize "the role that others play on the development of authenticity" Luthans et al (2006. p.44). The authentic self is developed often through interactions with others and therefore has a relational, and socially constructed, aspect to it. Parents, spouses, friends, leaders, mentors, peers and associates can all contribute to, or hinder, one's authenticity. For example, reinforcement of self expression, support for being oneself, acceptance of one and other people's strengths and limitations and tolerance of other's thinking can contribute to an environment where authenticity can be enhanced through internal comprehension and external expression of one's actual, true self. Alternatively, controlled situations that lack free expression are likely to impede the authentic self (Harter 2002). What role do others play in the developing of business students' authenticity given that many of them are not in the workforce in a current leadership position?

In summary, authenticity is self referential in nature and implies that knowing oneself, in order to be true to oneself, is a focus of self awareness and is key to authenticity. It is only as a person knows themselves and are able reflect on this information and process it accordingly, that they are able relate to others in an open and transparent manner and behave according to their own beliefs. Psychological accounts of authenticity are derived from human growth and development perspectives and see individual experience as key to development, similar to Grints' "phronesis" of learning via experience. Moreover, people are rarely authentic or inauthentic; authenticity is non dualistic and dialectic in nature (Luthans \& Avolio 2005) and can be recognized in moments or experiences of authenticity, or times of inauthenticity; can be viewed as stable or developmental and can be enhanced in social interactions or impeded through these interactions. Using traditional methods of teaching authentic leadership (such as techne and episteme) negates the ability for students of leadership to use their own experience of relationships, non dualism and dialectic forces in learning and development of authentic leadership to gain phronesis i.e. wisdom and insight into the authentic self.

“.....leadership has many voices and many ways to push and pull individuals...because of this you need to be who you are, not trying to emulate somebody else" (George 2003, p. 130).

However, the call for authentic leadership development aimed at the individual level of experience (and therefore phronesis) is lacking. Furthermore leadership developmental programs continue to grow without research 
and validation of the methods used and as Sinclair (2007) states, many lack rigour and critique, and methods of realistic appraisal.

The purpose of this study is to provide a quasi experimental analysis of student learning of authenticity in leadership. The process was threefold: firstly to redesign reflective learning to encompass authenticity triggers for reflections, secondly to use these reflections as the basis of writing a "Best Authentic Self" narrative (which included goal setting as part of a development plan) and finally assessment of students' narratives to ascertain if there were themes that emerged in aiding the development of authentic leadership for students.

\section{METHOD}

\section{Sample}

Thirty, year two, degree students enrolled in an elective leadership course towards a Business Studies degree participated in the research. Students were able to opt out of the research if they wished. Students were not advised of the research project until the end of the course. At that time students were asked to consent to their work being included in the research. All students participated in the project. Students were allocated a nominal identifier from 1-30.

\section{Procedure}

The initial project was divided into two areas: trigger events for experiential learning, leading to the second student project, writing of a "Best Authentic Self" narrative (that included goal setting). The goal being student's "Best Authentic Self" narrative would be aided by the 'trigger events' in journaling. The third aspect was a content analysis of students Best Self exercise to gain insight into themes in developing student authenticity- this is described in detail later.

\section{Part One - Reflective Learning and Authenticity Triggers}

To encourage leadership learning and growth, Sinclair (2007) uses an approach to teaching experiential based leadership, developed from Kolb (1987) which incorporates the learning (c.f. teaching) development of leadership. This includes:

- $\quad$ Reflection. Students dig into their own history investigating their own path as a leader and reflect on major (and minor) life experiences and values and assess how they have learned about behavior, its outcomes for themselves and their own leadership. They also reflect on their histories and project how they can develop further in leadership from their past. As such learning is from experience and this implies that learning comes from students' experiences outside the classroom and everyday observations and experiences.

In terms of becoming aware of issues in 'authenticity' and leadership Cooper et al (2005) suggested we include triggers and events when authenticity was developed and challenged. Therefore the current samples of students were also required to use the above frame work, and to:

- Incorporate into the reflection and experience aspects of 'learning leadership' times when they believed they acted with authenticity and also when they viewed their 'authenticity' may have been challenged.

To aid this reflection, "trigger events", designed by Cooper et al (2005) to capture authentic experience, are described in Table 1, and include the following:

1. Understand important life events that trigger growth

2. Trigger events can be sensational or routine

3. Understanding that trigger event can be artificial triggers

4. Culminations of small events that may over time reach a threshold that is characteristic of that leader. 
Explanation and examples were given to the students as part of the reflective exercise handout. Cooper et al (2005) emphasized the relevance triggers and these were explained in detail to students. Students were required to identify and reflect on 20 incidents that challenged or developed their authenticity using the reflective learning cycle. As Cooper (et al 2005) suggested it is the "interaction of the trigger event and personal insight that matter..." (pg 22).

Using the above experiential and reflective based framework, students undertook journaling and diarying of their (authentic) leadership experiences. Thus 'a person's own trigger events' (Kolb 1987) outside of the classroom became the learning that is involved in authentic leadership development.

\section{Part Two - "Best Authentic Self" Exercise}

As researchers have suggested that authenticity is developmental in nature, that possible selves can be developed into true selves, the students at the end of the course, and once they had finalized their 20 reflections, wrote a "Best Authentic Self" narrative, adapted from the "Best Self" exercise developed by Peterson (2006).

Students were required to review and reflect on their journal entries and to describe their experience/s of 'being authentic'; times where it had grown or thwarted, why this was so, and any goals they wanted to set from there. Peterson (2006) and Shamir \& Eillam (2005) used the life history and self narratives in leader development. The rationale being that individual accounts of relevant events across time, can develop a self-narrative for the individual that has a coherent connection among events. Shamir \& Eillam (2005) suggest that life narratives allow the developing authentic leader to see that one's life events are not simply as a set of unconnected events and that narratives attempt to understand life events as systematically related. The linking of discrete events gained from the journal/reflective exercise, allowed students to provide a life narrative that had a sensibility to it and previously disconnected events then 'become a sensible result of a life-story' (Shamir \& Eilam 2005 p 470).

Therefore, the reflections gained from trigger events, provided the events that fed into the "Best Authentic Self" exercise and established connections between those events into a coherent, unfolding process. The final narrative therefore gives the (learning) authentic leader a meaning system i.e. values, convictions, experiences, that have shaped them and from which they are able to feel, think and act and from which to analyze and interpret meaning and self understanding, Shamir \& Eilam (2005). The developing leader then has a point of view regarding their own authenticity that is personal, developed from personal experiences, personal reflection and personal meaning, with the opportunity to set personal developmental goals.

\section{Findings Presented from a Range of 30 Students' Journals}

- $\quad$ Trigger 4 (culmination of event/s). A student who was party to embezzling in an organization over 10 years ago. The student identified years of feeling uneasy at the situation. When looking back on (now) realizing that this was because they were 'not able to live with themselves....that it is not even a fear of being caught, but being caught up in it all that sickens me'

- $\quad$ Trigger 2 (negative sensational event). An experience of holding onto one's beliefs and leaving an organization because of expectations that ran contrary to that person's values and beliefs. This student was required to micromanage a person out of an organization, rather than pay out redundancy or go through a performance management process. Instead they resigned.

- Trigger 1 (important life event). Moving to a foreign country. "Doing without my family to support me", feelings of being alone, followed by a sense of growing awareness, "that I am capable of being on my own..."

- Trigger even 2 (positive sensational event). Being the person alone or the lone voice on an issue within an organization during restructuring "I stood up for what I believed in, and thought I would be shot down in flames, instead I got promoted!! .... They said to me we need people here that are prepared to stand up for what they believe in...."

- $\quad$ Trigger even 3 (artificial triggers). In class Values Exercise. "what I found is that the Schwartz model is true for me...I value relationships over many other things..' 


\section{Example of Student Narrative}

Students built their "Best Authentic Self" narratives around the trigger events. A sample is provided that demonstrates the movement from trigger event to narrative:

"being true to myself, my beliefs and values has been clarified so much for me. My "Best Authentic Self" is a person who recognizes the role and influence of others on who I am. 12 of my entries discuss this in various forms..... therefore my "Best Authentic Self" is about the role and value of enhancing and valuing sincerely key and beneficial relationships at work and through peers and friends. I believe this reflects myself, as in past I experienced this.......my authentic goals for the future come from this...specifically...."

\section{Evaluation of Project}

Student private feedback forms by way of end of course evaluation, indicated that the course was one of the "most challenging yet relevant they had undertaken towards their degree" (qualitative comment). In comparison to the previous year, this form of "assessment" that was student led aimed at developing phronesis indicated the project was successful. For example:

- $\quad$ Linking course content ( $100 \%$ of class at 'extremely satisfied')

- Developing a holistic knowledge of leadership (i.e. students talked about the link between theory and practice and reality (qualitative comment)

- $\quad$ Relevance and meaningfulness for students (100\% of class at 'extremely satisfied')

\section{Secondary Narrative Analysis}

As part of the rationale to enhance learning of authentic leadership, the author also undertook content analysis of students' "Best Authentic Self" exercises to ascertain if any commonalities emerged in student authenticity development. An overwhelming finding was the role of relationships on the development of authenticity. However the nature and role of those relationships varied. For example:

\section{Relationships (Influence of, and on, Others)}

"I believe that my "Best Authentic Self" is one who focuses on relationship........ my family and friends are so important to me and they have helped to mould me into the person I am now and having their relationships will influenced my leadership style - recognizing the importance of people and relationships...Jobs may come and go but the relationship that you from along the way will always be there, there are not that many people who stay in their jobs where they haven't formed any positive relationships anyway...As a leader creating positive exchanges with others is the key for me, and for getting anywhere in life....no one likes the dictator/autocratic leader..."

\section{Relationships v Task Orientation (Overcoming the True Self-building A True Self)}

"From creating the journals of reflections I have been able to really think about my "Best Authentic Self" and I would describe it as being built around people and relationships....surprised when reflecting on task or relationship orientated leadership, that I am slightly more task focused. .... Maybe I am more task orientated naturally... but my values also influence my orientation towards taking greater notice of the relationship and the value of these as a leader."

\section{Relationships (Counter Concerns - courage Not to Listen)}

“.... relationships (with whanau ${ }^{1}$ and hapu $^{2}$ ) are key, life is built around this... I value relationships as a component of success and try to strive to develop relationships with people that are as strong as family bonds...My

\footnotetext{
${ }^{1}$ Whanau - Maori for family and extended family.

${ }^{2} \mathrm{Hapu}$ - Maori for extended family and community.
} 
authentic self knows this, but for me my authentic leadership and self is also about the other part to that .... many people told me not to try to study...not to come to do a degree as I probably wouldn't do well and my decision was wrong. I prevailed against others ideas of me and resisted against them in my decision to study and this is a major motivator for me...I guess that is that I value relationships but also that I need to have courage and faith in my own decisions and abilities...value relationships but trust myself I suppose..."

\section{Relationships (Value of Honesty)}

"I believe that I have great values and beliefs that will help guide me along my future leadership journey. .... without these values and my beliefs about what is right and wrong I don't think I could make good decisions and also have a good attachment to the repercussion of decisions/actions. That's why I believe as a leader I need to have a strong morale conviction as you know who you are and what you believe in so you make the right decisions for yourself and your course.... The huge part of my authentic self are my values is being true and honest to myself and others about these values..."

\section{LIMITATIONS}

The nature of quasi experimental design suggests that replication may not be easily enacted. However the assessment instructions provide for a common method or starting point. A further limitation is that this approach to learning authenticity may be culturally bound, such that those in Asian countries may prefer a teacher centred approach to assessment and outcomes (Spreitzer et al 2009). Therefore relying on one's personal experiences may be difficult to implement in a more global education environment. However, given the initial positive feedback from students, research in other cultures that replicate this study may provide feedback that may strengthen the project.

\section{DISCUSSION}

Student evaluations of the learning aspect of authentic leadership indicated that a positive and highly personal learning experience had been had. Student examples provided outline the various aspects of authentic leadership and a range of experiences that demonstrate the learning of authentic leadership. Analysis of student's "Best Authentic Self" exercises demonstrated the key role of relationships in the development of leader authenticity, a previously unknown fact. By understanding the importance of relationships, educators may be able to frame triggers to more accurately engage relevant reflections. Further, in the second stage of this project the authors intend to add 'relationships'* as a further trigger (item 5) to be reflected on in the student journal aspect of the course.

\section{FINAL SUMMARY}

In a world of change and complexity, leadership students are often forced out into workplace situations with limited understanding of themselves in relation to these complexities. Traditional methods of teaching leadership, such as the techne and episteme, do not adequately prepare our future leaders for this world. The importance of authenticity in leadership has been recognised in leadership research; however, developing authenticity is under-researched from a student or learner-centred approach. This study provides some preliminary results of a learner-centred leadership development programme that had encouraging results. The method of doing so and an evaluation of this method demonstrate the advantages for developing a holistic approach to learning authentic leadership. 
Table 1 - Learning Authentic Leadership

Trigger events and possible use/explanation

1. Major Life Events.

Many discussion of authentic leadership describe trigger events in the life of leaders which had significant impact on their world view and leadership style. For example Mother Teresa and Bill George illustrate this concept. Mother Teresa coming across a dying women in India in 1948, she stayed with this women and for her life devoted time to helping the poorest of the poor. Bill George and the loss of his mother and fiancé are cited in his book on authentic leadership as trigger events. Bennis and Thomas (2002) in their book agree that the ability to overcome adversity and become stronger is one of the attributes of exceptional business leaders. They define 'crucibles of leaders' as 'a transformative experience through which an individual comes to a new or an alerted sense of identity'. (pg 6). Their interviews with top executives revealed that most could recount stories of critical life events that shaped their ability to lead others - including illness in childhood etc.. These individual showed an ability to learn from experience, and insight through self awareness that is characteristic of authentic leaders.

2. Trigger events may be dramatic and high profile events in one's life AND they may be less sensational. Both can aid the personal development that leads to authentic leadership. The importance of triggering life events can be death, divorce, relocation, redundancy or new work situations. Or Trigger events may also include more routine events such as reading an important book, watching a movie, discussions with peers or mentors that has a profound impact on the way one thinks and about their life and career.

3. Finally trigger events may also be artificially created in an intervention-type setting. For example the implicit association test (IAT) may work as a trigger event. An individual may not think that they harbor tendencies to be racist or sexist, but undertaking review and insight may reveal hidden aspects of the self. Doing the IAT may be a genuine way of making the individual more self aware. Additionally if this information is disturbing to the person, then the activity may serve as a catalyst for them to devote more conscious thought to their daily clarity and decisions.

4. Alternatively trigger events may be ones that are a 'culmination of smaller events which accumulate' over time until a threshold level is reached which evokes behaviors that are characteristic of authentic leaders. Authentic leadership in this sense may be evolutionary rather than revolutionary. For example being in a workplace and seeing changes that become manifest in the self, relocating and becoming more ingrained into the culture of anew country etc.,

\section{AUTHOR INFORMATION}

Maree Roche is a Principal Academic Staff member at the Waikato Institute of Technology, Hamilton, New Zealand. Maree's area of research and teaching specialization include Leadership, Organizational Behavior and Workplace Wellbeing. Of particular interest is a focus on the growing area of positive organizational behavior and positive psychology, and the benefits of this for leaders and employee wellbeing.

\section{REFERENCES}

1. Ardichvili,D., \& Manderschid, K. (2008) Emerging Practices in Leadership Development . Advances in Developing Human Resources, Vol.10. Nov 5. P. 619 -631.

2. Avolio, B. J., \& Gardner, W. L. (2005). Authentic leadership development: Getting to the root of positive forms of leadership. The Leadership Quarterly, 16(3), 315-338.

3. Avolio, B. J., Gardner, W. L., Walumbwa, F. O., Luthans, F., \& May, D. R. (2004). Unlocking the mask: a look at the process by which authentic leaders impact follower attitudes and behaviors. The Leadership Quarterly, 15(6), 801-823.

4. Cooper, C. D., Scandura, T. A., \& Schriesheim, C. A. (2005). Looking forward but learning from our past: Potential challenges to developing authentic leadership theory and authentic leaders. The Leadership

Quarterly, 16(3), 475-493.

5. Dychtwald, K., \& Morison, R. (2006). Workforce crisis (p. 269). Harvard Business Press

6. Endrissat, N., Müller, W. R., \& Kaudela-Baum, S. (2007). En Route to an Empirically-Based Understanding of Authentic Leadership. European Management Journal, 25(3), 207-220.

7. Erickson, R. J. (1995). The importance of authenticity for self and society. Symbolic Interaction, 18(2), $121-144$.

8. Erickson, T. (2009). Why generation X has the leaders we need now. Harvard Business Press, Sunday July 19.

9. Gardner W L, Avolio B J, Luthans F, May D R, Walumbwa F. (2005). Can you see the real me?? A selfbased model of authentic leader and follower development. Leadership Quarterly, 16(3), 343-372. 
10. George, B. (2003). Authentic leadership: Rediscovering the secrets to creating lasting value. San Francisco: Jossey-Bass.

11. George, B., Sims, P., McLean, A. N., \& Mayer, D. . (2007). Discovering your authentic leadership. Harvard Business Review, 85(2), 129-130, 132-138, 157.

12. Goffee, R., \& Jones, G. (2002). Managing authenticity: the paradox of great leadership. Havard Business School Review, 83(12), 86-94.

13. Grint, K. (2007). Learning to Lead: Can Aristotle Help Us Find the Road to Wisdom? Leadership, 3(2), $231-246$.

14. Grover, S. L., \& Moorman, R. H. (2007). Grasping the Meaning and Interpretation of Integrity in Business Leadership. European Management Journal, 25(3), 167-170.

15. Harter, S. (2002). Authenticity. In Handbook of positive psychology (pp. 382-394). Oxford, UK: Oxford University Press

16. Harvey, P., Martinko, M. J., \& Gardner, W. L. (2006). Promoting Authentic Behavior in Organizations: An Attributional Perspective. Journal of Leadership and Organizational Studies, 12(3), 1-11.

17. Heidegger, M. (1962). Being and time. Macquarrie J., \& Robinson, E. (Trans.). New York: Harper and Row.

18. Holland. K. (2009, March 15). Is it time to retrain business schools? The New York Times.

19. Ilies, R., Morgeson, F. P., \& Nahrgang, J. D. . (2005). Authentic leadership and eudaemonic well-being: Understanding leader-follower outcomes. The Leadership Quarterly.

20. Luthans, F., Youssef, C., \& Avolio, B. (2007). Psychological capital: Developing the human competitive edge. Oxford, UK: Oxford University Press.

21. Luthans, F., Vogelgesang, G. R., \& Lester, P. B. (2006). Developing the Psychological Capital of Resiliency. Human Resource Development Review, 5(1), 25-44.

22. Luthans, F., Avey, J. B., Avolio, B. J., Norman, S. M., \& Combs, G. M. (2006). Psychological capital development: Toward a micro-intervention. Journal of Organizational Behavior, 27, 387-393.

23. Luthans, F., Avolio, B. J. (2005). The psychological capital of Chinese workers: Exploring the relationship with performance. Management and Organization Review, 1(2), 249-271.

24. Macik-Frey, M. Quick, J. C. \& Cooper, C. L. (2008). Authentic leadership as a pathway to positive health. Journal of Organizational Behavior, 30, 453-458.

25. McKenna, B., Rooney, D., \& Boal, K. B. (2009). Wisdom principles as a meta-theoretical basis for evaluating leadership. The Leadership Quarterly, 20(2), 177-190.

26. Michie, S., \& Gooty, J. (2005). Values, emotions, and authenticity: Will the real leader please stand up? The Leadership Quarterly, 16(3), 441-457.

27. Mazutis, D., \& Slawinski, N. (2008). Leading Organizational Learning Through Authentic Dialogue. Management Learning, 39(4), 437-456.

28. Novicevic, M. M., Harvey, M. G., Ronald, M., \& Brown-Radford, J. A. (2006). Authentic Leadership: A Historical Perspective. Journal of Leadership and Organizational Studies, 13(1), 64-76.

29. Peterson, C.M. (2006). A Primer in Positive Psychology. Oxford University Press.

30. Shamir, B., \& Eilam, G. (2005). "What's your story?" A life-stories approach to authentic leadership development. The Leadership Quarterly, 16(3), 395-417.

31. Shirey, M. R. (2006). Authentic leaders creating healthy work environments for nursing practice. American Journal of Critical Care, 15, 256-267.

32. Sinclair, A. (2007). Leadership for the disillusioned: Moving beyond myths and heroes to leading that liberates. Sydney: Allen Unwim.

33. Sosik, J. (2009). Values in Authentic Action. Group \& Organization Management, 34(4), 395-431.

34. Spreitzer, G., Stephens, J.P., \& Sweetman, D. (2009) The best reflected self experiment with adolescent leaders: exploring the psychological resources associated with feedback source and valence. The Journal of Positive Psychology. Vol4. No.5 p 331-348.

35. Time (2008) The Price of Greed. (September 19.) Pages 18-26.

36. Vella-Brodrick, D. A. \& Page, K. M., J. (2009). Positive leadership: Accentuating and cultivating human resources. In Contemporary perspectives on leadership: focus and meaning for ambiguous times (1st ed.). Prahran Vic.: Tilde University Press.

37. Walumbwa, F. O., Avolio, B. J., Gardner, W. L., Wernsing, T. S., \& Peterson, S. J. (2008). Authentic Leadership: Development and Validation of a Theory-Based Measuredagger. Journal of Management, 34(1), 89126. doi: 10.1177/0149206307308913. 
NOTES 